\title{
La permanencia del regionalismo en la literatura brasileña contemporánea ${ }^{1}$
}

\author{
André Tessaro Pelinser \\ Doctor en Estudios Literarios \\ Universidade Federal do Rio Grande do Norte \\ https://orcid.org/0000-0001-9756-0116 \\ andre.pelinser@ufrn.br \\ Márcio Miranda Alves \\ Doctor en Teoría Literaria y Literatura Comparada \\ Universidade de Caxias do Sul \\ https://orcid.org/0000-0001-6455-7332 \\ mmalves2@ucs.br
}

\section{Resumen}

Este artículo analiza la permanencia de marcas del regionalismo en la prosa de la literatura brasileña contemporánea. Considerado superado por la crítica literaria y renegado por los escritores, el regionalismo entró a la historia de la literatura brasileña como sinónimo de arte de baja calidad estética. Sin embargo, se percibe que los temas regionales nunca dejaron de ser materia para la narrativa ficcional brasileña, desde Guimarães Rosa, Erico Verissimo y Josué Guimarães, hasta Luiz Antonio de Assis Brasil, Antônio Torres y Milton Hatoum. Se observa que la diferencia entre el presente y el pasado reside en el énfasis dado por los escritores al contexto y al espacio regionales, orgullosos, en un primer momento, de las particularidades regionales y, en la contemporaneidad, preocupados por la problematización de los contrastes culturales. Se concluye que la literatura brasileña contemporánea debe mucho a la tradición regionalista, sin que ello implique cuestionamientos de calidad estética, y que le corresponde a la crítica investigar los temas y las formas de la narrativa como claves de interpretación para problemas históricos que perduran.

Palabras clave: literatura brasileña contemporánea; región; regionalismo.

\footnotetext{
${ }^{1}$ Procedencia del artículo: Este artículo es resultado del proyecto de investigación "Modulações contemporâneas do Regionalismo literário brasileiro", desarrollado por el "Núcleo de Estudos em Narrativa Ficcional Brasileira", en la Universidade Federal do Rio Grande do Norte y en la Universidade de Caxias do Sul.
} 


\section{The permanence of Regionalism in Brazilian contemporary literature}

\section{Hbstract}

This article analyses the permanence of traces of Regionalism in Brazilian contemporary fiction. Regarded as outdated by literary criticism and disavowed by writers, Regionalism has entered the history of Brazilian literature as synonymous with art of low aesthetic quality. Nevertheless, regional themes have never ceased to be subject matters for Brazilian fictional narrative, from Guimarães Rosa, Erico Verissimo, and Josué Guimarães, to Luiz Antonio de Assis Brasil, Antônio Torres, and Milton Hatoum. It is possible to notice that the difference between the present and the past resides in the emphasis assigned by writers to regional context and space, at first vainglorious about regional singularities, and concerned, in contemporaneity, with problematizing cultural contrasts. It can be concluded that Brazilian contemporary literature is indebted to the regionalist tradition, which does not imply questioning its aesthetic quality, and that it is up to literary criticism to investigate themes and narrative forms as keys to interpret persisting historical problems.

Keywords: Brazilian contemporary literature; region; regionalism.

Recibido: 15 de febrero del 2021. Aprobado: 26 de abril del 2021

Artículo de reflexión

https://doi.org/10.25100/poligramas.v0i53.11576

¿Cómo citar este artículo en MLH? - How to quote this article in MLA?

Miranda Alves, Márcio y André Tessaro Pelinser. "La permanencia del regionalismo en la literatura brasileña contemporánea" Poligramas 53 (2021): e.2311576 Web. Fecha de acceso (día, mes en mayúscula y abreviado, y año). 


\section{Recorridos de la crítica}

Si la cuestión regional forma parte de la historia brasileña, es necesario reconocer que las alteraciones que su abordaje ha sufrido se muestran lentas en comparación con la importancia del tema, de manera que, en términos teóricos y literarios, todavía parecen insuficientes. Recientemente, la materia comenzó a ser encarada de una manera detenida en los estudios literarios. Para el crítico, traductor y escritor José Clemente Pozenato, sería posible afirmar que en los últimos 20 años la idea de región transitó de una visión negativa a una, por lo menos, positiva (149). Tomándose en consideración que el estudio de Pozenato data de 2003, esa transición estaría más o menos localizada en la década de 1980. De hecho, son de la década anterior algunos trabajos del propio Pozenato ${ }^{2}$ y de Ligia Chiappini ${ }^{3}$ al respecto del regionalismo, los que analizan el tema desde nuevas perspectivas $y$, sin duda alguna, contribuyen a un cambio de evaluación. Sin embargo, el autor parece, tal vez, demasiado optimista al sostener que "antes era necesario demostrar que el Regionalismo no consistía en una visión estrecha del proceso social, en cualquiera de sus dimensiones", y que "hoy, la percepción de las relaciones regionales es vista como un modo adecuado de entender cómo funciona, o puede funcionar, el proceso de mundialización de todas las relaciones humanas" (Pozenato 149).

En lo que se refiere al arte literario, la regionalidad ${ }^{4}$ de ciertas obras y autores sigue causando dificultades a los críticos, ya que no son raras las evaluaciones que unen argumentos sobre el resultado estético de los textos a problemas identificados en el nivel del contenido. Ejemplo elocuente de la permanencia del problema es la obra de Milton Hatoum: mientras que Eurídice Figueiredo traza posibles relaciones entre sus textos con una tradición regionalista vista desde la óptica de lo contemporáneo (Figueiredo 44-45), Allison Leão parte de las reflexiones de Tânia Pellegrini, presentes en «Milton Hatoum e o regionalismo revisitado" [Milton Hatoum y el regionalismo revisado], para problematizar y refutar la vinculación del escritor a esa vertiente. El propio escritor, por su parte, rechaza esas relaciones, diciendo que ha intentado "evitar no solo el exotismo, sino también el regionalismo, que, muchas veces, puede

\footnotetext{
2 Su ensayo O regional e o universal na literatura gaúcha [Lo regional y lo universal en la literatura gaucha], agraciado con una mención honrosa en el concurso promovido por el Instituto Estatal del libro, fue publicado en 1974, con elogios de Guilhermino Cesar.

${ }^{3}$ La autora publica Modernismo no Rio Grande do Sul: materiais para seu estudo [Modernismo en Río Grande do Sul: materiales para su estudio] y Regionalismo e Modernismo: o caso gaúcho [Regionalismo y Modernismo: el caso gaucho en 1972 y 1978] en 1972 y 1978, respectivamente.

${ }^{4}$ Entendida aquí como "particularidades culturales de un espacio regionalizado o que se regionaliza" (Arendt 115).
} 
transformarse en una camisa de fuerza, una forma de inscribir el texto en un área geográfica" (Marcondes). Desde su punto de vista, además, los trazos de localismo y de las circunstancias históricas están siempre presentes en la obra, dado que el escritor estaría siempre rondando sus orígenes. De eso se puede inferir que la sensación incómoda de Hatoum no es con los elementos abarcados por el regionalismo, pues estos él los asume como esenciales para la obra, sino con la propia categoría -con el rótulo-, lo que puede explicarse por el peso negativo que posee y por cuánto puede pesar para la pérdida de capital literario todavía hoy. En suma, el autor reivindica un alcance, pero su incomodidad personifica un problema casi tan tradicional como la propia historiografía literaria brasileña.

El proceso de formación por el que pasaron las letras brasileñas, si es examinado desde esa perspectiva, provee importantes indicios para explicar la situación presente, ya que el problema representado por la matriz regionalista deriva de las discusiones al respecto de la nacionalidad y de las obras gestadas por el Romanticismo ${ }^{5}$. El repertorio crítico consolidado desde entonces, paulatinamente asoció la idea de región a lo tacaño, a lo pequeño y culturalmente inferior, contaminando todo lo que a ella se le vincula. Cabe, hoy, indagar en qué medida ese orden de factores interfiere en el juicio del que es capaz de ofrecer un arte que se defina como regionalista. Es esencial cuestionar hasta qué punto un autor rechaza la marcación de la idea de regionalismo por cuenta de los preconceptos unidos a esta vertiente. De lo contrario, se debe asumir que hablar de aquello que está al margen de los centros culturales implica una necesaria pérdida de calidad artística.

Al final, si, como apunta Pozenato, en las últimas décadas la idea de región ha transitado de una visión negativa hacia una menos positiva, parece evidente que ese tránsito todavía no se dio en el campo literario, que sigue atando la noción de regionalismo a una concepción reducida del quehacer artístico, según la cual la calidad de la obra está casi que inmediatamente determinada por la estrechez del objeto del cual ella se ocupa. Esa idea, que no está desarrollada ni registrada de esta manera, pero es así practicada, puede ser sintetizada en la siguiente ecuación propuesta por Fischer: "ciudad grande + modernización + vanguardia = arte verdadero; sin cualquiera de estos ítems, tenemos arte viejo, irrelevante, despreciable, merecedor -como máximo- de una nota de pie de página" (134). Para Fischer, son las "idealizaciones" las que impiden una mejor visibilidad del regionalismo, el cual debería ser

\footnotetext{
${ }^{5}$ Para una discusión historiográfica en relación con el tema, ver Pelinser.
} 
sometido a "una lectura más histórica, a una lectura rigurosamente materialista" (138). Justamente porque eso no acontece, Fischer defiende pura y simplemente que la "idealización (negativa)" llamada regionalismo debería ser "barrida para el basurero del pensamiento crítico" (138).

Sin embargo, como no se puede minimizar la permanencia de la matriz crítica que considera al regionalismo como una opción literaria necesariamente portadora de limitaciones, antes de descartar del todo la categoría de análisis, tal vez sea provechoso examinar las líneas de fuerza de este debate. Este no ocurre por casualidad, en la medida en que lecturas en ese sentido se remontan al siglo XIX, como lo demuestra Lajolo (Lajolo), y recorren todo el siglo XX, siendo reafirmadas de tiempo en tiempo por críticos como Machado de Assis, Alceu Amoroso Lima, Lúcia Miguel Pereira, Antonio Candido y Alfredo Bosi, entre otros, sea de forma explícita o por medio de preámbulos que llevan a la misma conclusión. Por un procedimiento que toma las fallas de obras individuales como pertenecientes a toda una vertiente, se extienden las críticas a tal punto que las obras de calidad no pueden ser vinculadas a la corriente regionalista. Es lo que se nota en un texto de julio de 2013, publicado en la sección "Literatura» de la revista ¡Bravo!, en el que el autor indaga ya en la llamada a la lectura, inmediatamente abajo del título, si "¿Todavía tiene sentido clasificar a la obra de Graciliano Ramos y de otros escritores nordestinos como regionalista?" (Gama).

Para defender la calidad artística de la obra de Graciliano Ramos y de otros autores nordestinos, sosteniendo que el llamado "surto nordestino» es en realidad mucho más que un momento pasajero de la historia literaria brasileña, Rinaldo Gama recurre a críticos y escritores reconocidos y cuestiona el rótulo «regionalista» que se les impuso a estos. Para el autor, la afirmación de la innegable calidad de Graciliano Ramos parece pasar por su desvinculación de esta corriente, ya que "después de su novela de estreno, Graciliano Ramos lanzaría apenas tres libros más en ese género: San Bernardo (1934), Angustia (1936) y Vidas secas (1938); que, sin embargo, representarían el punto alto del 'surto nordestino' y comprobarían la vocación del autor hacia más allá del regionalismo" (Gama).

Del mismo modo, Gama señala la opinión de autores contemporáneos, para quienes la afiliación regionalista es todavía más incómoda, sinónimo de intereses y alcances reducidos: 
“En el caso de algunos escritores, principalmente en el de José Lins do Rego, el rótulo 'regionalista' tiene sentido porque él se aplica a nombres que siguieron la receta del sociólogo Gilberto Freyre en el Manifiesto de 1926, el que defendía que la ficción y hasta la poesía debían registrar, ante todo, trazos de la cultura regional, con alguna cosa de estética. Es decir, una literatura sociológica y antropológica, sin grandes compromisos con el arte; una enorme equivocación", argumenta el ficcionista pernambucano Raimundo Carrero, autor de A Minha Alma É Irmã de Deus [Mi alma es hermana de Dios]. "La crítica tiene la manía de colocar ese rótulo en todo escritor nordestino. Nunca fui regionalista. No copio vidas, invento vidas, aunque sea a partir de mi región”, afirma Carrero, que resalta su identificación con el paraibano Ariano Suassuna y el Movimiento Armorial, "cuya preocupación mayor es la estética, tomando lo regional apenas como metáfora (Gama).

Por su parte, Ronaldo Correa de Brito, cearense radicado en la ciudad de Recife y autor de Galilea, manifiesta una opinión levemente diferente, dado que, para este autor:

El criterio regional no puede ser reductor porque el paisaje o el lugar son, muchas veces, artificios para el ficcionista para tratar de cuestiones metafísicas, que se relacionan con todos los hombres, de cualquier región. La geografía que conozco, donde nací y vivo, es siempre mi referencia para atrás, la memoria a la que recurro incluso cuando la historia ocurre en Nueva York o en Fez (Brito ctd. en Gama).

Milton Hatoum, como ya fue mencionado, demuestra incomodidad en relación con la vertiente a la que fue algunas veces asociado:

El amazonense Milton Hatoum, encargado de la conferencia de abertura de la Flip sobre Graciliano -en un curioso contrapunto entre un autor creado bajo el signo de las aguas y otro inspirado en el territorio del desierto-, considera no apenas extemporáneo sino también inadecuado el abordaje regionalista. "Hace tiempo que esa expresión fue usada en Estados Unidos para nombrar la literatura del sur. Irónicamente, William Faulkner se transformó en uno de los mayores autores norteamericanos del siglo pasado. Algo semejante acontece aquí. Pero el punto central de la literatura no es el origen del escritor ni el lugar en el que ocurre la narrativa, sino el lenguaje; por eso Graciliano Ramos fue grande", afirma (Gama). 
En este caso específico, llama la atención la «ironía» de que Faulkner se haya transformado en uno de los mayores autores de Estados Unidos, al mismo tiempo que su obra recibía el malhadado rótulo de regionalista. En lugar de «ironía», ese ejemplo debería demostrar justamente la imprecisión que es considerar todo aquello que se refiere a la región como algo inevitablemente menor. La ironía, en realidad, se encuentra en la reprobación de Hatoum al regionalismo valiéndose de un ejemplo comprobatorio de la calidad que puede tener cualquier pieza de arte, esté afiliada a los elementos y temas de una región o no, ya que, como dice el propio autor a continuación, se trata de lenguaje.

No obstante, a juzgar por los estudios de Ligia Chiappini, la permanencia de trazos regionalistas en la ficción contemporánea no debería sorprender. La autora afirma haber, a lo largo de sus investigaciones sobre el regionalismo en América y en Europa, confirmado la sospecha de que este fenómeno, siempre considerado superado por la crítica literaria brasileña, no solo continuaba vivo en 1995, cuando publica su texto, sino que se había transformado en tema de investigaciones bastante actuales, "ganando una amplitud mayor en la intersección de los estudios literarios y artísticos, históricos e etnológicos" (153). En ese trabajo, Chiappini intenta "problematizar juicios críticos estereotipados que generalizan hacia la tendencia como un todo las limitaciones estéticas e ideológicas de la mayor parte, reconozco, de las obras que el regionalismo ha producido" (154). A fin de cuentas, ¿no sería ese enfoque el responsable por el sentimiento de incomodidad de Milton Hatoum, un escritor contemporáneo, al ver su obra relacionada con tal tradición? Del mismo modo que esa actitud dificulta el examen de la obra del escritor amazonense, crea obstáculos a la investigación sobre el legado de otros grandes nombres, como João Guimarães Rosa.

Walnice Nogueira Galvão revela que la correspondencia privada de Guimarães Rosa registra el rechazo del minero por algunas de las características de la literatura que le era contemporánea y que venía dominando el escenario nacional, lo que incluía las vertientes regionalista y espiritualista. Aunque no sea posible saber exactamente a qué escritores Guimarães Rosa se refiere en las cartas, ya que los nombres están censurados, para él la literatura brasileña, "con pocas excepciones, es un valor negativo, una caca de perro en la alfombra de una sala" (Galvão 115). Es necesario resaltar que esta opinión de Guimarães Rosa, destinada a un tío, surge -justamente- en el auge del embate entre el «regionalismo de 
30» y la novela espiritualista, con predominio de aquel sobre esta, cuando una parte significativa de la producción literaria tiene en las cosas del ambiente rural el tema preferencial para la ficción. El estreno de Rosa, en este contexto, termina haciendo surgir "un manifiesto contra la mala literatura" (Galvão 113), lo que en la práctica va a reforzar los argumentos, por parte de la crítica, en relación con que existe incompatibilidad entre la buena literatura y los temas relacionados con el campo. Si bien la ficción de Guimarães Rosa abarca temas y espacios comúnmente asociados al regionalismo, por presentar una manera de escribir inédita y de alto nivel, el autor sería elevado a la condición de "universal», mientras que aquellos que no alcanzaron el mismo patrón estético son relegados a la posición de «regional». Desde entonces, el legado de Guimarães Rosa para la literatura contemporánea tal vez esté encubierto por el estigma relacionado con la tradición regionalista.

En lo que se refiere al regionalismo literario brasileño, parece que hay una resistencia en considerarlo partícipe activo de los procesos de formación y de consolidación de una tradición. Juliana Santini señala la laguna presente en los estudios literarios referentes a esa vertiente en el periodo posterior al llamado "ciclo nordestino de 1930» y destaca la crítica de Ligia Chiappini sobre la insuficiencia del concepto de "conciencia de subdesarrollo» empleado por Antonio Candido para justificar la presencia del regionalismo en las letras brasileñas. Santini sostiene que, aunque Chiappini "reafirme esa necesidad de reinterpretación de los caminos recorridos por la literatura regionalista después del ciclo nordestino, la autora deja abierta la cuestión, restando menos una solución que una interrogación" (79). En su acepción, uno de los méritos de Chiappini "es lanzar un desafío que llama la atención hacia la urgencia de encontrar un lugar para esa producción literaria, comenzando por el emprendimiento de situar la obra de Guimarães Rosa en relación al regionalismo literario brasileño" (Santini 79).

Considerada la posición canónica ocupada por el escritor minero, se instaura un problema para situarlo en relación con una tradición menospreciada, como lo es el regionalismo. Para Santini, la propia

(...) posibilidad de permanencia del regionalismo en la literatura brasileña producida después de la década de los años 30 del siglo XX permanece en suspenso, sin que la crítica literaria haya atado a esa laguna un hilo que complete o simplemente la coloque como incompatible, de manera que parece que no hay consenso -a veces, ni siquiera una discusión- al respecto del problema, que se hace más abarcante si son 
tomadas en consideración obras producidas posteriormente al contexto en que se incluye a Guimarães Rosa, como el trabajo de José Cândido de Carvalho o, más recientemente, de autores como Francisco J. C. Dantas, Milton Hatoum y Ronaldo Correia de Brito (Santini 79).

El problema es que, como bien apunta Ygor Raduy, si en un primer momento es revolucionario el modo de representación de lo regional sugerido por Guimarães Rosa, luego él es legitimado por la crítica e inserido en el canon literario, transformándose en un clásico por ser «universal» (73). En ese proceso, la novedad es enyesada por el patrón y sometida por el discurso historiográfico, que intenta aprehenderla a partir de las categorías existentes y con eso, a veces, falla en percibir los procesos de transformación de la tradición. De esta manera, parte de la renovación propuesta por la ficción de Guimarães Rosa ha quedado silenciada en los estudios críticos, que todavía hoy tienen dificultades para identificar las resonancias de la obra del escritor minero en la literatura de sus pares, incluso cuando estos la anuncian en entrevistas y en congresos, lo que ha enmascarado ciertas mutaciones de la tradición regionalista.

Curiosamente, escritores de afuera de las fronteras no manifiestan el mismo resentimiento al reconocer su deuda con Guimarães Rosa. Por ejemplo, el mozambiqueño Mia Couto, uno de los principales exponentes de la literatura occidental contemporánea, ya enfatizó la influencia de Rosa sobre su prosa poética, más precisamente por cuenta de la oralidad del sertón minero transpuesta a la narrativa ficcional. Mia Couto cuenta que fue presentado a la obra de Guimarães Rosa -inicialmente con el volumen de cuentos Primeras historias- por Luandino Vieira, escritor angolano que ya había declarado que había sido influido por el minero.

Aquello fue un abalo sísmico en mi alma, porque allí estaba lo que yo y otros estábamos buscando. Había allí no solamente una relación con la lengua, sino también con otras cosas que están más allá de ella, una tentación de crear en el lenguaje un universo propio, como si el lenguaje se apropiara de la historia, de la geografía, creando otra realidad. Y esa otra realidad también era importante para nosotros, que estábamos viviendo la lógica de un estado centralizador, que aplastaba las lógicas rurales, ese mundo del sertón, que no es del orden de la geografía, sino de la suma de varias culturas. La lectura de Guimarães Rosa para mí fue como un roto. Gran Sertón: veredas es aquel libro al que se regresa constantemente, capaz de retratar un mundo entero (Couto). 
A partir de testimonios como este, no se necesita mucho esfuerzo para concluir que el reconocimiento de la influencia de Guimarães Rosa sobre escritores de otros países, en este caso africanos, tiene que ver justamente con el hecho de que en esos países la «cuestión» de lo regional recorre otras veredas. Es decir, hasta donde se sabe, la historia de la literatura en esos lugares no reconoce el temario regional como algo identificado con una obra de supuesta calidad inferior y, por este motivo, no existe la posibilidad de avergonzarse para los escritores por asumir cierta identificación con un autor marcadamente regionalista. Evidentemente, las literaturas africanas reflejan procesos históricos diferentes, y lanzar miradas en ese sentido daría un nuevo rumbo a la discusión, lo que no viene al caso en este momento.

Lo que importa comprender, para el análisis aquí propuesto, es que el discurso crítico, desde el lanzamiento de Sagarana, en 1946, manifiesta una relación conturbada con las características comúnmente asociadas al regionalismo, ora reconociendo, ora negando su presencia en la ficción de Guimarães Rosa. En lugar de fomentar nuevas percepciones críticas acerca de la literatura producida con base en espacios regionales, la obra de Guimaraes Rosa parece haber contribuido, involuntariamente, a la consolidación de matrices de pensamiento que niegan a lo regional el estatuto literario. En la fortuna crítica del autor merece destaque la creación de un paradigma de interpretación interesado en la "superación» de lo regional, presente sobre todo en dos textos de Antonio Candido: en la primera reseña de Sagarana, de 1946, y en el ensayo "Literatura y subdesarrollo», de 1970. En esos dos momentos, se instaura y se refuerza la idea de que la buena ficción -y la literatura brasileña en general- necesita «Superar» lo regional para, entonces, alzarse a lo «universal» 6.

\section{Recorridos de la literatura}

Pasando, en principio, a lo largo de este debate, en un texto que discurre sobre tres novelas de Milton Hatoum y mapea una serie de resonancias de otras obras en la escritura de ese autor, María Zilda Cury señala una de las más importantes funciones del arte en general, de la literatura más específicamente: "A través de su extrañeza y de su desubicación, su ficción abre espacio y hace que se escuchen voces nativas, reprimidas, las voces de aquellos considerados como

\footnotetext{
${ }^{6}$ Para una discusión detallada sobre el lugar ocupado por Guimaräes Rosa en la discusión sobre el regionalismo literario brasileño y sobre cómo su recepción crítica terminó por profundizar en el problema, ver Pelinser.
} 
afásicos culturales" (46). La autora recuerda, además, que la autobiografía de Edward Said, titulada Out of Place, defiende que el intelectual debe hablar a partir del margen de la producción de las ideas, de forma que pueda evitar el pensamiento central y tomar en consideración a los marginados de la sociedad (Cury 49), y sitúa en esa característica el triunfo de Hatoum. Destaca su capacidad de "mirar al otro, sabiéndose no ser el otro. Sentir con el otro, sabiéndose no ser el otro. Responsabilizarse por el otro, radicalmente, como quiere todavía Levinas, responsabilidad como superación ética de la percepción de la alteridad" (Cury 59).

Entonces, es interesante que precisamente ese autor protagonice una relación tan problemática con el regionalismo. A fin de cuentas, se pueden verificar en su obra ciertos trazos de localismo, una especie de "localización excesiva» de las tramas que permite su inserción en una tradición desventurada, al mismo tiempo en que se identifica en la visión de mundo de sus textos una capacidad singular de dar voz al otro. En prácticamente todas sus obras, sean novelas o cuentos, la valorización del espacio y sus elementos regionales indican la preocupación de crear un universo ficcional en el que el hombre y el medio están íntimamente conectados, y en el cual las idiosincrasias de aquel no raro son determinadas por la percepción de este. Esa relación, así, puede ora indicar un sentimiento de identificación entre ambos, ora un sentimiento de rechazo. El resultado de la factura apunta justamente a las contradicciones entre mundos que se contraponen, como atraso y modernidad, floresta y ciudad, conservadurismo y vanguardismo, etc.

Un síntoma de esas relaciones se puede encontrar en los personajes Mundo y Arana, en Cenizas del Norte. Ambos son artistas plásticos; el primero es aprendiz del segundo. El conformista Arana invierte en la carrera del arte decorativo para adornar los hogares de la clase media alta con temas regionales de la Amazonia, destacando la exuberancia de la flora y de la fauna. El rebelde Mundo, comprometido con las causas sociales e inconforme con las problemáticas de la población, prefiere el arte de combate, pensado y producido para causar impacto e incomodidad a los mandatarios. Los motivos del arte de Mundo no dejan de ser regionales, pues también trabajan con problemas locales, pero se construyen en modelos críticos y no ufanistas. Esa diferencia entre los dos, sin embargo, no nace por casualidad. Mundo pasa las vacaciones con la familia en Río de Janeiro, donde conoce a otros artistas, nuevas formas de expresión y una visión de la sociedad que se choca con el Manaus de Arana. En una conversión con el amigo Lavo, Mundo comenta sobre el maestro Arana: 
"No es más el mismo", dice con aspereza. "Es más, nosotros no somos más los mismos, Lavo. El atelier de él es una fábrica de cuadros y esculturas. Arana renegó hasta de aquella jaula quemada llena de osos y césped seco... Decía que era una obra muy crítica, pero hoy ve que es fútil. Una fase experimental, ya pasó... Dijo eso mismo, y además, se rió. Arana se transformó en un bajo comerciante del arte. Quiso que él repitiera todo sobre mi proyecto. Entonces: ¿por qué el Campo de cruces era apenas una provocación? No respondió. Es un tipo muy miedoso. Ahora él decora gabinetes, manda regalos a oficiales y a políticos..." (Hatoum 163-164).

El proyecto "Campo de cruces» al que se refiere Mundo consiste en la instalación de 80 cruces de madera quemada en el conjunto habitacional Nuevo Eldorado, en protesta contra la muerte de un amigo durante las actividades del Colegio Militar. Considerada como la mayor obra urbanística del alcalde Zanda, coronel del Ejército que pretende modernizar Manaus con una reforma urbana, el residencial Nuevo Eldorado es un conjunto de casas sin terminar y sin cloacas, ni agua, ni luz o recolección de la basura, distribuidas por las calles barrosas y distantes del centro urbano. "Los moradores del Nuevo Eldorado eran prisioneros en su propia ciudad" (Hatoum 148).

Esas contraposiciones entre los artistas Mundo y Arana son síntomas de la profundidad de la reflexión del ambiente regional en Milton Hatoum. Al oponer dos proyectos artísticos distintos de figuras amazonenses, el escritor señala justamente las contradicciones inherentes al proceso de reconocimiento y aceptación de lo local frente a lo «universal». Son dos formas de encarar el lugar de la región de pertenencia frente al resto del mundo: una cerrada alrededor de su eje y la otra abierta a nuevas posibilidades. Mientras uno reivindica el derecho de reforzar una identidad mitificada, proveyendo a los pares lo que ellos buscan y están dispuestos a pagar (negociando lo regional como mercancía), el otro actúa en el sentido inverso, en una lucha ardua para engarzar la realidad de afuera para adentro. Con este fin, Arana se cierra en su atelier en Manaus, ciudad que podría llamarse «metrópoli regional» por causa de su separación geográfica en relación con el centro del país; por su lado, Mundo transita por otras metrópolis, reconocidamente "globales»-y, por extensión, ¿universales?-, como Río de Janeiro, Berlín y Londres. En suma, las contraposiciones caras al regionalismo están todas puestas ahí, presentadas con brillantez formal y estética. En ese sentido, causaría extrañeza la incomodidad 
de Milton Hatoum frente al regionalismo, en caso de que no personifique un problema casi tan tradicional como la propia historiografía brasileña y que perdura en el siglo XXI.

Desde otra llave de lectura, ¿no sería posible indagar si no sería justamente ese el papel del regionalismo, el de estar al margen y hablar con y por aquellos que no tienen acceso al centro? Tal vez sea lícito pensar el desarrollo de esa vertiente de las letras brasileñas a partir de ese lugar marginal, tomando en cuenta, es obvio, la posición culturalmente central de los primeros autores. No tendría sentido defender que un hombre como José de Alencar estuviera dedicado a darle voz al indio, al gaucho, al sertanejo, en una perspectiva culturalista en los términos actuales. José de Alencar tenía un proyecto literario bien conocido y su producción refleja la sociedad y la historia del Brasil monárquico en búsqueda de una identidad propia, cuyos "defectos" de composición, cuando ocurren, "son los del tiempo", como apunta Candido (546). Sin embargo, tal vez sea posible pensar en otro tipo de aproximación al objeto narrado en el caso de Euclides da Cunha, partiendo de un punto de vista que, sin duda, busca registrar la atrocidad cometida contra un grupo social minoritario, regionalmente localizado y largamente desconocido, e inscribir su voz en la historia de una nación. Desde esa perspectiva, Euclides da Cunha habría hecho en Los sertones lo que los historiadores todavía ni imaginaban, que es profundizar sobre el particular para revelar un contexto más amplio; esto, también, va a reflejarse en la forma literaria a partir del romance social del 30. Curiosamente o no, la obra de Euclides da Cunha no acostumbra a ser asociada al regionalismo, aunque la materia regional sea la base que solidifica su narrativa, y, muchas veces, con una denotación más personal de lo que se supondría.

Del mismo modo, en el caso de Guimarães Rosa, aunque no lo haya declarado con tono de denuncia, se puede cuestionar en qué medida la alianza de lo moderno y lo arcaico profesada por el conjunto de la obra contribuye a comunicar los dramas de una parte de Brasil de la que una parcela central y elitista de la sociedad solamente toma conocimiento cuando el arte consigue impactar e inserirse en el imaginario. A propósito, cabe retomar un texto bastante desconocido, pero profundamente relevante, para que se comprenda el universo narrativo de Guimarães Rosa. En «Pie duro, sombrero de cuero», publicado en un periódico, en 1952, y, posteriormente, recogido en Ave, palabra, Rosa presenta una profesión de fe acerca de la figura del sertanejo en la cultura brasileña. Al discurrir sobre un encuentro de vaqueros en el interior del estado de Bahía, el escritor no se esconde de alabarlos como una especie de símbolo 
nacional y sugiere la necesidad de "ofrecerles la fórmula etológica, el diseño biográfico, el capital magnífico de sus vivencias; definiendo en un plano ideal la ejemplar categoría humana del vaquero, con el fin de fundirla en el cuerpo de nuestros valores culturales" (Rosa, Ave... 173). Consciente de su tono laudatorio, Guimarães Rosa agrega una nota de pie de página en la que señala que estamos exageradamente "sonsos y escépticos", y por miedo a la opinión ajena perdemos la capacidad de "admirar y alabar, o incluso el módico deber de reconocer", lo que le permite la osadía: "si exagero, justicia para la exageración" (Ave... 173).

No sorprende, pues, que los deslizamientos entre lo arcaico y lo moderno, y las superposiciones de sentido consecuentes que se verifican en la ficción de Guimarães Rosa, jamás van a privilegiar uno sobre el otro. En sus textos, el mundo del sertón es reelaborado por una prosa moderna y responsable -para retomar la idea de Levinas referida por Cury-, dotada de una profunda percepción de la alteridad y fundada en una ética incapaz de subvalorar al sertanejo y su espacio. En la obra rosiana, el sertón no aparece como apenas un telón de fondo para la discusión de otros temas, ni tampoco es figurado con interés exótico. Antes, construye la propia estructura de las narrativas y ofrece la base sobre la cual emergen múltiples significados. En la literatura de Guimarães Rosa, en fin, la posibilidad de formular interpretaciones en correspondencia con las más diversas mitologías, la filosofía tanto occidental como oriental, la historia de Brasil, entre otras, advienen de la forma como una región muy particular de Minas Gerais es ficcionalizada. Con esta clave, se puede comprender la aserción de Riobaldo, para quien "el sertón es del tamaño del mundo" (Rosa, Grande Sertão 89).

Justamente de ese punto resulta la importancia de la obra de Guimarães Rosa para las modulaciones contemporáneas de los espacios regionales en la ficción brasileña, aunque la crítica literaria haya presentado dificultades, a lo largo del tiempo, para ubicarla correctamente en el conjunto de la literatura nacional y de sus ciclos. En lo restante, la propia falta de claridad en las definiciones del término regionalismo, comprendido como tradición literaria, contribuye a explicar la posición ambigua del escritor minero en relación con su vinculación con esa vertiente, como puede ser verificado en la famosa entrevista a Günter Lorenz. En esta, Guimarães Rosa problematiza los conceptos de «regionalismo» y "regionalista», asegurando que no le gustaría ser considerado en Alemania un Heimatschriftsteller, "ya que es lo que para usted correspondería al concepto de 'regionalista'". Pero, al mismo tiempo, el autor se presenta como un "hombre del sertón" y asegura estar "plenamente de acuerdo, cuando usted me sitúa como 
representante de la literatura regionalista; y aquí comienza lo que yo ya había dicho antes: es imposible separar mi biografía de mi obra" (Lorenz 65-66).

Es importante notar que, en la entrevista, el término "regionalista» viene empleado entre comillas en el primer pasaje, cuando Rosa reniega de él, y sin comillas en la segunda, cuando lo acepta. Es decir, la posición del escritor queda ambigua y refleja la compejidad que el tema alcanzó en la literatura brasileña. Además, aunque la discusión no estuviese en el horizonte de Guimarães Rosa en esos términos, es importante destacar que Heimatschriftsteller no corresponde con exactitud a la idea de "escritor regionalista" en los términos que se usan en Brasil, sino a la de «escritor de/sobre la tierra natal». Según Norbert Mecklenburg:

Quien pretende comprender críticamente el desarrollo de la Literatura sobre la tierra natal en el siglo XX necesita, por lo tanto, diferenciar cuidadosamente: literatura moderna que formula artísticamente el problema humano de la tierra natal; literatura regionalista, que trata de la aldea o de la provincia; literatura romántica-ideológica-agraria que, en Alemania, representó una corriente literaria anti modernista, de finales del siglo hasta la época del Nacional-Socialismo (179-180 ${ }^{7}$.

Algo semejante ocurre en Río Grande do Sul a partir de la publicación de El tiempo y el viento, de Erico Verissimo. Considerado por la historiografía como uno de los exponentes del regionalismo de 1930, Erico también rechazó la clasificación de su obra como regionalista, aunque los elementos regionales relativos al hombre del campo, a la tierra, al paisaje y a las costumbres de la pampa formen parte de la base temática que sostiene su ficción. En su libro de memorias, Erico admite sentir admiración por "trabajos aislados" de autores como João Simões Lopes Neto, Darcy Azambuja, Cyro Martins y Vargas Neto, pero afirma que intentó alejarse del regionalismo, que, según él, es un "género literario . . . limitado y, en ciertos casos, con un cierto olor y una inmovilización anacrónica de museo" (288). Para Erico Verissimo, la prueba de esa ausencia de lo regional en El tiempo y el viento reside en su desconocimiento de la "jerga gaucha", pues detestaba la vida rural, desconocía la vida en las estancias y no sabía andar a caballo (288).

${ }^{7}$ Cursivas del original. 
En la trilogía, la «denuncia social» del 30 aparece en los momentos de conflicto, como en las guerras y las revoluciones, justamente para confrontar los modelos literarios de la generación anterior, que buscaba exaltar los valores de fuerza y coraje del gaucho moldado por la lucha armada. En ese proceso de reescritura de un modelo de identidad anclado en el mito, Erico Verissimo relativiza el ideal maniqueísta que insistía en colocar al gaucho brasileño en posición de enfrentamiento en relación con el extranjero, ya fuese este castellano o lusobrasileño de otras regiones de Brasil $^{8}$.

En otros momentos históricos, la narrativa del escritor gaucho privilegia grupos sociales hasta entonces minoritarios (como los inmigrantes europeos), uniéndolos en un presente que traduce de manera más sensata el proceso de formación de identidad de la región. Desde esa perspectiva, todos los nuevos agentes sociales son contemplados en un mismo cuadro, pero algunas imágenes simbólicas del pasado romántico no son del todo abandonadas, pasando por un proceso de resignificación más allá de una celebración ingenua. No es por casualidad que la tradición del regionalismo de Erico Verissimo -cuya temática no se resume al campo, sino que también incluye a la ciudad en rápida transformación- se transformó en modelo casi obligatorio para los escritores gauchos posteriores, y algunas semejanzas relacionadas con los temas y las formas de abordaje pueden ser encontradas en los coterráneos Josué Guimarães, Luiz Antonio de Assis Brasil, Tabajara Ruas, Letícia Wierzchowski y Sérgio Faraco, entre otros, sin que ese «modelo» temático implique necesariamente una literatura de menor valor.

En la década de 1970, Josué Guimarães rehace la saga de los inmigrantes alemanes en la novela A ferro e fogo [A hierro y fuego], interrumpida por la muerte del escritor antes de que completara el tercer volumen. A semejanza de lo que Erico Verissimo había realizado en relación con el proceso de formación identitaria del gaucho en el Continente de San Pedro, Josué Guimarães se concentra en los dramas de adaptación del extranjero, aquel que necesita vencer las barreras del idioma, de la cultura y de la geografía en un ambiente inhóspito. La soledad de los campos, los peligros de los constantes conflictos armados y el achatamiento del sujeto

\footnotetext{
8 Es justo subrayar que diferentes interpretaciones pueden surgir, dependiendo de la perspectiva analítica de episodios o lances aislados de la unidad de la trilogía, en el sentido de apuntar hacia la existencia de cierta "glamourización identitaria» en El tiempo y el viento. Pesavento, por ejemplo, afirma que "puede parecer herejía decir que la narrativa ficcional de Erico se entrelace a este vies, que coloca en un pasado atemporal y glamourizado el patrón de referencia de Río Grande, pero Erico es hijo de su tiempo, y su escritura es fechada. Entendemos que se observa en su obra el delineamiento de ciertos valores y 'defectos bonitos', que hacen del gaucho un arquetipo seductor y que dan, al menos, una 'compensación simbólica' para pérdidas reales" (101-102).
} 
común frente a los movimientos históricos son presentados de una manera que no deja margen para heroísmos de cualquier naturaleza. La superación del medio no ocurre sin sufrimiento y dolor, prevaleciendo un tono de denuncia que lleva al lector a ver al proceso inmigratorio desde una perspectiva bien diferente de aquel que apenas exalta las conquistas de los conquistadores europeos.

A pesar de una innegable proximidad de forma y tema entre Josué Guimarães y Erico Verissimo, el primero siempre negó cualquier influencia de este o de cualquier otro autor gaucho. Guimarães afirma que busca emplear "un lenguaje lo más nacional posible" (6), justamente para compensar todo lo regional que no consigue negar en su ficción. Para él, así como para Verissimo, como ya fue apuntado, las marcas de lo regional son exclusivamente una cuestión lingüística, o sea, «modismos gauchos», de acuerdo con sus propias palabras. De esa manera, el autor de A ferro e fogo lucha para crear un «lenguaje nacional» que lo libere del estigma de lo regional (gaucho), al mismo tiempo que la narrativa se presenta con muchos diálogos en alemán. Por ese motivo, Josué Guimarães prefiere vincular su obra a la de Machado de Assis, Graciliano Ramos y Jorge Amado?.

En la misma época, surge la literatura de Luiz Antonio de Assis Brasil, otro escritor cuyo conjunto de la obra mantiene puntos de contacto con la tradición regionalista. Estrenó en 1976, con Um quarto de légua em quadro [Un cuarto de legua en cuadro], y desde entonces publicó muchas novelas identificadas con los temas regionales, siempre explorando las contraposiciones entre el hombre de campo y el de la ciudad, atraso y modernidad, memoria y olvido. En sus obras, los principales personajes de la historia de Río Grande do Sul están en diálogo constante con la fábula romanesca, muchas veces sirviendo de arquetipos para la representación de coroneles en medio del proceso de modernización, en una especie de arco que revela la ascensión y la caída de un grupo social que se proyecta hacia la historia a partir de la Revolución farroupilha (1835 - 1845), y sucumbe, justamente, con la Revolución de 1930.

\footnotetext{
${ }^{9}$ La aproximación que Josué Guimarães realiza de su obra con la de Jorge Amado no deja de ser un contrasentido. Aunque sea comúnmente vinculado a una idea de brasilidad, el escritor bahiano siempre fue considerado por la crítica un autor regionalista y, aunque en su obra se puedan distinguir al menos cinco temas, de acuerdo con lo que indica Alfredo Bosi, la narrativa de Amado difícilmente sería interpretada como representante de un "lenguaje nacional" (406). Es decir, en las novelas de Jorge Amado permanecen elementos típicamente regionales, sea en el lenguaje, sea en la temática. Esa es una de las marcas evidentes que ayudan a explicar el éxito del escritor entre los lectores.
} 
Más recientemente, en un panel compuesto por El pintor de retratos, La margen inmóvil del río, Música perdida y Figura en la sombra, cuatro novelas agrupadas bajo el título Visitantes al Sur, Assis Brasil señala otro modo de convergencia espacial. Nuevamente marcado por el recurso de personalidades históricas ficcionadas, el conjunto de narrativas coloca en escena personajes multifacéticos e imposibles de aprehender en su totalidad, que, construidos por la mano de la ficción contemporánea, se encuentran en permanente tránsito, en incesante movilidad, aunque habiten siglos pasados. Comparecen a los enredos, con mayor o menor peso, las figuras ficcionadas de Aimé Bonpland y Alexander von Humboldt, en Figura en la sombra; el fotógrafo francés Félix Nadar, en El pintor de retratos; el emperador don Pedro II, en La margen inmóvil del río, y los músicos José Mauricio y Joaquim José de Mendanha, ambos en Música perdida. Acompañando la trayectoria de estos y de los demás personajes, los textos todavía señalan importantes eventos históricos, como la Proclamación de la República y la Revolución federalista.

Sin embargo, lo que aproxima a los protagonistas del cuarteto de novelas es justamente el hecho de que todos ellos, en algún momento de sus vidas, son visitantes del Sur. Provenientes de diversas partes del mundo y por las más variadas razones, los personajes de Assis Brasil, de alguna manera, terminan por aportar en tierras gauchas en momentos significativos de sus vidas, y, en el suelo de aquella región, encuentran experiencias que definirán sus existencias. En ese proceso, sus conflictos internos son contrapuestos a las características físicas, a la historia y a los habitantes del espacio con el cual comienzan a relacionarse. La singular extensión de la pampa gaucha surge, de esa manera, como vehículo de transformación, por lo que ninguno de los personajes pasa incólume. Sandro Lanari finalmente se transforma en fotógrafo, aunque para eso necesite testificar -y fotografiar- los horrores de la disputa entre chimangos y maragatos; el historiador de La margen inmóvil del río aprende a vagar por el Sur, como si estuviera en búsqueda de una nueva identidad, enfrentando la imposibilidad de aprehender la historia en su totalidad; el maestro Mendanha recupera su música perdida, aun cuando esto le cueste la vida; Aimé Bonpland encuentra su destino en la búsqueda por la yerba.

Para estos visitantes del Sur, por lo que todo indica, apenas en el transcurrir de una vida entera, en el entre-lugar del tránsito y en el aportar en nuevos espacios puede brotar alguna respuesta, aunque siempre sea provisoria e incompleta. Es necesario atravesar tiempo y espacio, el espacio específico de Río Grande do Sul, con su historia y su cultura. Por esa 
insistencia en la región del sur, incluso, Assis Brasil se alinea con la tendencia de la producción literaria actual de muchas veces profundizar en el espacio regional con un interés marcadamente culturalista. Por la factura que logra imprimirle a sus textos, huye de los estereotipos marcadamente convencionados como los característicos de las culturas regionales. De esa manera, en textos como los de este autor, la región no surge como un espacio que debe ser observado, sino como un complejo local de tránsito y de intercambios; como un punto apropiado para observar, en las entrelíneas de la subjetividad de los personajes, un espectro más amplio de acontecimientos.

En una clave distinta, pero igualmente interesada en abordar un espacio regional marcado por las consecuencias de prácticas de movimiento características de la contemporaneidad, se puede examinar la narrativa de Essa terra [Esa tierra], novela publicada por Antonio Torres en 1976. En esta se narra la historia de los hermanos Nelo y Totonhim, personajes cuyas vidas son profundamente alteradas por los flujos migratorios que marcaron las relaciones sociales en el sertón a lo largo del siglo XX. El relato de la migración, que ganó destaque en obras como O quinze [El quince], de Rachel de Queiroz, o Vidas secas, de Graciliano Ramos, que señaló la tendencia neorrealista de la Novela del 30, reaparece, pero con los polos invertidos, en la ficción de Torres. Esa fase de la tradición literaria regionalista, que surgió politizada y contestataria, denunciando los resultados perversos de la problemática división de poder en Brasil y de los procesos de modernización nacional, siempre prontos a construir ruinas, es escenificada nuevamente en Esa tierra mediante la figura del hermano que deja la pequeña cuidad de Junco y parte en dirección a San Pablo; sin embargo, este es forzado a retornar, apenas años más tarde, para cometer suicidio en la tierra natal.

Pensada en el conjunto de una tradición literaria, la inversión propuesta por Antonio Torres posee un impacto no despreciable en la serie literaria brasileña. Representado de maneras distintas por los románticos, por la ficción del fin de siècle, por los novelistas de la década del 30, y recuperado en un enfoque inesperado por Guimarães Rosa ya en la mitad del siglo XX, es innegable que el sertón se ha transformado en un importante topos literario en Brasil. Dicho de modo reductor, el tema pasó de una perspectiva idealizada, en su inicio, a una visión progresivamente crítica, conforme a su desarrollo. El resultado de ese desarrollo, perceptible en la obra de Torres, inaugura una nueva fase en la literatura brasileña, de acuerdo con lo que identifica Ítalo Moriconi, sustituyendo la experiencia del sertanejo en el sertón por la experiencia 
del sertanejo en el sudeste. "En Esa tierra, tal experiencia aparece por lo negativo, es presencia ausencia, así como el propio personaje Nelo en la novela es presencia ausente, narrada por los ojos del hermano-más-joven-que-quedó" (Moriconi 8).

Sin embargo, tal vez no sea exacto considerar que hoy el sertón "se transformó en la periferia de las grandes ciudades" (Moriconi 8). En realidad, tales espacios no se confunden, aunque tengan cada vez más puntos de contacto elaborados por la ficción contemporánea. Tanto en la periferia urbana como en ese sertón marcado por contradicciones, esa literatura ha intentado iluminar la condición humana frente a la iniquidad y, muchas veces, a la impotencia. Pero mientras la literatura de la primera mitad del siglo XX todavía apuntaba a una posibilidad de esperanza, al vislumbrar el horizonte de la migración, la contemporaneidad, consciente de sus resultados reales, apunta más a un proceso abortado. Trágicamente, la inversión del ciclo migratorio protagonizada por Nelo no representa un reencuentro con un espacio de pertenencia, ya que el sujeto que partió ya no es el mismo que regresa, pero motiva toda la narración de Totonhim, poniendo en tela de juicio la propia relación con Junco, con el sertón, con la realidad cultural circundante. Así es como procede Esa tierra, ofreciendo nuevas modulaciones a la tradición literaria en la que se insiere.

\section{A manera de conclusión}

Parece, entonces, pertinente inquirir cómo la corriente regionalista puede haber caminado lentamente y según el imaginario de cada época, en el sentido de una aproximación mayor al individuo que está a margen de los centros urbanos y simbólicos. Puede ser relevante, en suma, responder en qué medida la tradición regionalista se transformó a tal punto que encarna hoy una perspectiva como aquella defendida por Edward Said, por la que el artista y el intelectual deben dominar la cultura, tal como es concebida por el centro, y poseer el capital simbólico necesario para enunciar con legitimidad, pero debe hacerlo a partir del margen y la mirada de quien está al margen. A fin de cuentas, la propia Manaus de Hatoum, la Santa Fe de Erico Verissimo o el sertón de Rosa solamente son "regiones» y poseen "particularidades" por ser vistas a partir de un centro económico, político y cultural bastante claro.

Atendiendo a lo anterior, esa perspectiva puede ser una alternativa viable para examinar la literatura contemporánea con una mirada más solidaria hacia sus recientes modulaciones temáticas y formales, buscando no encajarla en esquemas previamente concebidos de bueno y 
malo, sino investigando qué nuevas respuestas esta es capaz de ofrecer a los problemas que perduran. Con tal procedimiento, tal vez sea posible comprender mejor por qué razones los autores brasileños que utilizan materia regional temen a la vinculación con la tradición literaria regionalista. Por otro lado, esa aproximación puede mostrarse eficaz porque también lanza luces innovadoras sobre la producción literaria de los autores contemporáneos, quienes, por lo que parece, continúan produciendo literatura con la misma materia prima regional de sus antecesores. Le corresponde a la crítica, por lo tanto, más que establecer las debidas conexiones entre autores, obras y períodos literarios, para proveer interpretaciones que expliquen el fenómeno de la tradición regionalista brasileña a partir de paradigmas que rechacen la necesidad de «superación» del dato regional y que deshagan la relación de equivalencia que se creó entre «regionalismo» y «literatura de mala calidad».

Para esto, un camino oportuno se encuentra en la posibilidad de comprender el regionalismo, antes que nada, como una tradición literaria de larga duración en Brasil. Se trata, en primer lugar, de reconocer su permanencia en la contemporaneidad y de investigar las modulaciones por las que viene pasando. Enseguida, se lo debe tomar como un rótulo que designa un conjunto de obras cuya afinidad reside en recuperar y resignificar motivos y temas literarios característicos de una corriente literaria, a partir del trabajo con espacios, tipos humanos, imágenes y lenguajes intrínsecamente vinculados a esta. Procediendo de esa manera, será posible verificar que, en razón de las transformaciones del regionalismo con el paso del tiempo, la manera como los textos literarios regionalistas se apropian del material provisto por la tradición igualmente sufre mutaciones, de modo que la ficción actual ya no se presenta utópica o programática como en los siglos pasados. Esa comprensión serviría para aclarar que la simple vinculación al regionalismo no restringe -tampoco amplía- el alcance de una obra y, además, permitiría problematizar las propias estructuras de valoración del campo literario. 


\section{Referencias}

Arendt, João Cláudio. "Notas sobre regionalismo e literatura regional: perspectivas conceituais". Todas as Letras Z. Mayo/Ago. 2015: 110-126. Web.

Assis Brasil, Luiz Antonio de. A margem imóvel do rio. Porto Alegre: L\&PM, 2003. Impreso.

Assis Brasil, Luiz Antonio de. Figura na sombra. Porto Alegre: L\&PM, 2012. Impreso.

Assis Brasil, Luiz Antonio de. Música perdida. Porto Alegre: L\&PM, 2006. Impreso.

Assis Brasil, Luiz Antonio de. O pintor de retratos. Porto Alegre: L\&PM, 2002. Impreso.

Bosi, Alfredo. História concisa da literatura brasileira. São Paulo: Cultrix, 2011. Impreso.

Candido, Antonio. Formação da literatura brasileira: momentos decisivos, 1750-1880. Rio de Janeiro: Ouro sobre Azul, 2007. Impreso.

Chiappini, Ligia. "Do beco ao belo: dez teses sobre o regionalismo na literatura". Estudos Históricos. 1995: 153-159. Web.

Couto, Mia. "Personagem em busca de um autor". Entr. Ricardo Prado. Carta Capital, dez. 2010. Web.

Cury, Maria Zilda Ferreira. "Topografias da ficção de Milton Hatoum”. Topografias da cultura: representação, espaço e memória. Eds. Ravetti, Graciela et al. Belo Horizonte: Editora UFMG, 2009. 41-62. Impreso.

Figueiredo, Eurídice. "Literatura comparada: o regional, o nacional e o transnacional". Revista Brasileira de Literatura Comparada. 2013: 31-48. Web.

Fischer, Luís Augusto. "Conversa urgente sobre uma velharia - uns palpites sobre vigência do Regionalismo". Cultura e Pensamento. Dez. 2007: 127-142. Web.

Galvão, Walnice Nogueira. Mínima mímica: ensaios sobre Guimarães Rosa. São Paulo: Companhia das Letras, 2008. 91-118. Impreso.

Gama, Rinaldo. "Vidas secas e outras vidas". Revista Bravo! Jul. 2013. Web.

Guimarães, Josué. Josué Guimarães. 3. ed. Porto Alegre: IEL, AGE/ULBRA, 1988. Impreso.

Hatoum, Milton. Cinzas do Norte. São Paulo: Companhia das Letras, 2005. Impreso.

Lajolo, Marisa. "Regionalismo e história da literatura: quem é o vilão da história?". Historiografia brasileira em perspectiva. Ed. Freitas, Marcos Cezar. São Paulo: Contexto, 1998. 297327. Impreso.

Leão, Allison. "Milton Hatoum: regionalismo revisitado ou renegado?". XII Congresso Internacional da ABRALIC: Centro, Centros - Ética, Estética. Jul. 2011. Web. 
Lorenz, Günter. "Diálogo com Guimarães Rosa”. Guimarães Rosa. Ed. Coutinho, Eduardo. Rio de Janeiro: Civilização Brasileira, 1991. 62-97. Impreso.

Marcondes, Marleine Paula y Ferreira de Toledo. "Espaço e preconceito nas obras de Hatoum". VIII Congresso luso-afro-brasileiro de ciências sociais. Set. 2004. Web.

Mecklenburg, Norbert. "Regionalismo literário em tempos de globalização". Regionalismus Regionalismos: subsídios para um novo debate. Eds. Arendt, João Claudio y Roberto Gerson Neumann. Caxias do Sul: Educs, 2013. 173-195. Impreso.

Moriconi, Italo. "Prefácio". Essa terra. Torres, Antônio. Rio de Janeiro: BestBolso, 2008. 7-10. Impreso.

Pelinser, André Tessaro. "Guimarães Rosa e o Regionalismo literário brasileiro: revisão crítica sobre um problema perene". Signo. Mayo/Ago. 2017: 2-19. Web.

Pelinser, André Tessaro. "Guimarães Rosa e seus precursores: regionalismo, deslocamentos e ressignificações". Tesis. Universidade Federal de Minas Gerais, 2015.

Pellegrini, Tânia. "A ficção brasileira hoje: os caminhos da cidade". Revista de Filología Románica. 2002: 355-370. Web.

Pesavento, Sandra Jatahy. "A temporalidade da perda". Erico Verissimo: o romance da história. Eds. Leenhardt, Jacques et al. São Paulo: Nova Alexandria, 2001. 89-102. Impreso.

Pozenato, José Clemente. Processos culturais: reflexões sobre a dinâmica cultural. Caxias do Sul: Educs, 2003. Impreso.

Raduy, Ygor. "Apontamentos sobre Guimarães Rosa e a prática historiográfica: desenraizamento e sacralização". Terra roxa e outras terras - Revista de Estudos Literários. 2006. Web.

Rosa, João Guimarães. Ave, palavra. 5. ed. Rio de Janeiro: Nova Fronteira, 2001. Impreso.

Rosa, João Guimarães. Grande sertão: veredas. 19. ed. Rio de Janeiro: Nova Fronteira, 2001. Impreso.

Santini, Juliana. "A 'Formação da literatura brasileira' e o regionalismo". O eixo e a roda: revista de literatura brasileira. Jan./Jun. 2011: 69-85. Web.

Torres, Antônio. Essa terra. Rio de Janeiro: BestBolso, 2008. Impreso.

Verissimo, Erico. Solo de clarineta. 20. ed. São Paulo: Editora Globo, 1995. v. 1. Impreso. 